\title{
Effects of Jia-Wei-Xiao-Yao-San on the Peripheral and Lymphatic Pharmacokinetics of Paclitaxel in Rats
}

\author{
Mei-Ling Hou, ${ }^{1}$ Chia-Ming Lu, ${ }^{1}$ and Tung-Hu Tsai ${ }^{1,2,3,4}$ \\ ${ }^{1}$ Institute of Traditional Medicine, National Yang-Ming University, No. 155, Section 2, Li-Nong Street, Taipei 112, Taiwan \\ ${ }^{2}$ Graduate Institute of Acupuncture Science, China Medical University, No. 91, Hsueh-Shih Road, Taichung 404, Taiwan \\ ${ }^{3}$ School of Pharmacy, College of Pharmacy, Kaohsiung Medical University, No. 100, Shih-Chuan 1st Road, Kaohsiung 807, Taiwan \\ ${ }^{4}$ Department of Education and Research, Taipei City Hospital, No. 145, Zhengzhou Road, Datong District, Taipei 103, Taiwan
}

Correspondence should be addressed to Tung-Hu Tsai; thtsai@ym.edu.tw

Received 15 January 2016; Accepted 16 February 2016

Academic Editor: José L. Ríos

Copyright (c) 2016 Mei-Ling Hou et al. This is an open access article distributed under the Creative Commons Attribution License, which permits unrestricted use, distribution, and reproduction in any medium, provided the original work is properly cited.

\begin{abstract}
Paclitaxel is effective against breast cancer. The herbal medicine, Jia-Wei-Xiao-Yao-San (JWXYS), is the most frequent prescription used to relieve the symptoms of breast cancer treatments. The aim of the study was to investigate the herb-drug interaction effects of a herbal medicine on the distribution of paclitaxel to lymph. A validated ultraperformance liquid chromatography with tandem mass spectrometry (UPLC-MS/MS) method was used to determine the paclitaxel levels in rat plasma and lymph after intravenous infusion of paclitaxel alone with or without 7 days of JWXYS pretreatment. The pharmacokinetic results indicate that paclitaxel concentrations in plasma exceeded those in lymph by approximately 3.6-fold. The biodistribution of paclitaxel from plasma to lymph was $39 \pm 5 \%$; however, this increased to $45 \pm 4 \%$ with JWXYS pretreatment. With JWXYS pretreatment, the AUC and $C_{\max }$ of paclitaxel in plasma were significantly reduced by approximately 1.5 -fold, compared to paclitaxel alone. Additionally, JWXYS decreased the AUC and $C_{\max }$ of paclitaxel in lymph. However, the lymph absorption rate of paclitaxel with or without JWXYS pretreatment was not significantly changed ( $27 \pm 3$ and $30 \pm 2 \%$, resp.). Our findings demonstrate that when paclitaxel is prescribed concurrently with herbal medicine, monitoring of the blood pharmacokinetics of paclitaxel is recommended.
\end{abstract}

\section{Introduction}

Cancer is a global health problem. Surgery, chemotherapy, and radiotherapy are still the major conventional cancer therapies [1]. Paclitaxel is a natural product used as a chemotherapeutic agent against various malignant tumors including ovarian, breast, and non-small-cell lung cancers. The antitumor activity of paclitaxel is attributed to microtubule stabilization [2]. Although chemotherapy and radiotherapy are effective treatments against cancer, these treatments can cause serious side effects and complications, including fatigue, pain, diarrhea, nausea, vomiting, and hair loss, that cannot be ignored $[1,3,4]$. Thus, increasing evidence demonstrates that herbal medicines can be used as adjuvant therapies to ameliorate the chemotherapy-induced side effects [57].

According to a survey from the National Health Insurance (NHI) database in Taiwan, Traditional Chinese
Medicine (TCM) is frequently prescribed to people with cancer as a remedy for alleviating symptoms or improving quality of life [8]. The results demonstrate that the Chinese herbal formula Jia-Wei-Xiao-Yao-San (JWXYS) is the most frequently prescribed formula for treating breast cancer $[8,9]$. Generally, JWXYS relieves climacteric symptoms including panic, dysphoria, and hot flashes in postmenopausal women [6]. Recently, JWXYS has been prescribed as an alternative treatment for chronic diseases $[6,8,9]$.

Paclitaxel is a P-glycoprotein (P-gp) substrate and is metabolized via cytochrome P450 (CYP) 2C8 and the 3A4 subfamily [10]. Coadministration of drugs that modulate the activity of CYP enzymes is likely to have undesirable clinical consequences $[5,11,12]$. The study suggested that oral administration of some phenolic substances might increase paclitaxel blood concentration during chemotherapy [13]. Various clinical factors including lymph node invasion and tumor size are essential in determining the best therapeutic 
option for breast cancer patients $[3,4]$. Differences in pharmacokinetics, and drug distribution in particular, may cause poor efficacy of the chemotherapeutic drug at the targeted site $[3,4]$. The pharmacokinetics of paclitaxel in rats and humans has been investigated [14-16]; however, information regarding the distribution of paclitaxel in lymph remains limited. In addition, JWXYS is the most frequent prescription used to relieve symptoms in women being treated for breast cancer [8]. It is possible that JWXYS and paclitaxel may interact to exhibit adverse effects in the clinic. Thus, the aims of the study are to investigate the pharmacokinetics of paclitaxel by UPLC-MS/MS in rats following intravenous infusion of paclitaxel and to explore whether pretreatment with JWXYS affects the pharmacokinetics and lymph distribution of paclitaxel. These results provide information crucial to conducting chemotherapy in combination with JWXYS.

\section{Materials and Methods}

2.1. Chemicals and Reagents. The chemicals paclitaxel, docetaxel, and tert-Butyl methyl ether (TBME) were purchased from Sigma-Aldrich Chemicals (St. Louis, MO, USA). LC/MS grade solvents were obtained from J.T. Baker, Inc. (Phillipsburg, NJ, USA), and chromatographic reagents were obtained from Tedia Co., Inc. (Fairfield, OH, USA). Sodium chloride was purchased from E. Merck (Darmstadt, Germany). Triple deionized water (Millipore, Bedford, MA, USA) was used for all preparations. The pharmaceutical herbal product JWXYS manufactured in accordance with Good Manufacturing Practice (GMP) for Chinese Crude Drugs was obtained from pharmaceutical companies in Taiwan and has been used medicinally for patients. JWXYS consists of roots of Angelica sinensis (Oliv.) Diels, rhizomes of Atractylodes macrocephala Koidz., roots of Paeonia lactiflora Pall., roots of Bupleurum chinensis DC or Bupleurum scorzonerifolium Willd., sclerotia of the parasitic plant Poria cocos (Schw.) Wolf, roots and rhizomes of Glycyrrhiza uralensis Fisch., root barks of Paeonia suffruticosa Andr., ripe fruits of Gardenia jasminoides Ellis, rhizomes of Zingiber officinale Rosc., and stems and leaves of Mentha haplocalyx Briq., with a weight ratio of $4: 4: 4: 4: 4: 2: 2.5: 2.5: 4: 2$, respectively [17]. The pharmaceutical herbal product, JWXYS, was purchased from Sheng Chang Pharmaceutical Co., Ltd. (Taipei, Taiwan).

2.2. UPLC-MS/MS. The UPLC-MS/MS analysis was performed using a Waters Acquity UPLC ${ }^{\mathrm{TM}}$ system (Waters, Manchester, UK) consisting of a binary solvent manager, an automatic liquid chromatographic sampler, and a Waters $\mathrm{Xevo}^{\mathrm{TM}}$ tandem quadrupole mass spectrometer equipped with an electrospray ionization (ESI) source. Separation was achieved using a Phenomenex Kinetex C18 analytical column $(100 \times 4.6 \mathrm{~mm}$, length $\times$ inner diameter, particle size of $2.6 \mu \mathrm{m})$ maintained at $40^{\circ} \mathrm{C}$ in a column oven. The mobile phase consisted of triple deionized water and methanol $(28: 72 ; \mathrm{v} / \mathrm{v})$ and the flow rate was set at $0.35 \mathrm{~mL} / \mathrm{min}$. The injection volume was $5 \mu \mathrm{L}$.

For operation in the MS/MS mode, the electrospray ion source was operated with polarity positive ion mode in a single run. The ESI parameters were set as follows: source temperature: $150^{\circ} \mathrm{C}$; desolvation temperature: $550^{\circ} \mathrm{C}$; desolvation gas flow: $1000 \mathrm{~L} / \mathrm{h}$. The optimized cone voltages $(\mathrm{CV})$ were $58 \mathrm{~V}$ for paclitaxel and $56 \mathrm{~V}$ for docetaxel. The multiple reaction monitoring (MRM) mode using specific precursor/product ion transitions was used for quantification. The molecular ions of paclitaxel and docetaxel were fragmented at collision energies of 28 and $26 \mathrm{eV}$ using argon as the collision gas. Ion detection was performed by monitoring the transitions: $m / z 876.4 \rightarrow 308.1$ for paclitaxel and $m / z 830.4 \rightarrow 549.2$ for docetaxel. Docetaxel was used as the internal standard (IS) for positive ion mode analytes. A MassLynx 4.1 software data platform was used for spectral acquisition, spectral presentation, and peak quantification.

2.3. Animal Experiments. All animal experimental protocols were reviewed and approved by the Institutional Animal Care and Use Committee (IACUC number: 1020716) of National Yang-Ming University. Male specific-pathogen-free Sprague-Dawley rats weighing $300 \pm 20$ g were obtained from the Laboratory Animal Center of the National Yang-Ming University, Taipei, Taiwan. Animals were provided free access to food (laboratory rodent diet 5P14, PMI Feeds, Richmond, IN) and water.

In accordance with published studies, the doses of paclitaxel and JWXYS for the animals were based on the human doses and were derived using the following conversion equation recommended by the US Food and Drug Administration guidelines: human equivalent dose $(\mathrm{HED}, \mathrm{mg} / \mathrm{kg})=$ animal dose $(\mathrm{mg} / \mathrm{kg}) \times\left(\right.$ animal $K_{m} /$ human $\left.K_{m}\right)$ [18]. Clinically, paclitaxel is given as intravenous infusion for at least three hours, and the maximum daily dose of JWXYS for human is $12 \mathrm{~g}$.

To investigate the herb-drug interaction effects of JWXYS on the pharmacokinetics of paclitaxel in rat plasma and lymph, paclitaxel was administered by intravenous infusion to rats with or without oral JWXYS at $1.23 \mathrm{~g} / \mathrm{kg}$ for 7 days. The commercial pharmaceutical powdered JWXYS was weighed and suspended in sterile water at the dosing volume of $10 \mathrm{~mL} / \mathrm{kg}$. JWXYS at $1.23 \mathrm{~g} / \mathrm{kg}$ was administered to each rat by oral gavage. At the 7th dose of JWXYS, rats were given $1 \mathrm{~mL}$ of olive oil by oral gavage thirty minutes preoperatively and then anesthetized with urethane $(1 \mathrm{~g} / \mathrm{kg}$, IP) for mesenteric lymph duct, jugular vein, and femoral vein cannulation. The purpose of the oral dosing of olive oil 30 mins before operation was to facilitate identification of the lymph vessels $[19,20]$. The procedure for the cannulation of the mesenteric lymph vessels was performed as previously described [21, 22]. The rats were administered $5 \mathrm{mg} / \mathrm{kg}$ of paclitaxel by intravenous infusion into the right femoral vein at the infusion rate of $2 \mathrm{~mL} /$ hour for 3 hours. Two hundred $\mu \mathrm{L}$ samples of blood were withdrawn from the cannula implanted in the jugular vein into heparin-rinsed vials at $0,15,30,60,120,180,185,195$, $210,225,240,270,300,330,360,390$, and $420 \mathrm{~min}$. The lymph was collected into heparin-rinsed vials at $30 \mathrm{~min}$ intervals. The mesenteric lymph rate during the $24 \mathrm{~h}$ period following surgery averaged $2.4 \pm 1.1 \mathrm{~mL} / \mathrm{h}$ [19]. In order to compensate the loss of body fluid, the rats were intravenously infused with normal saline at an infusion rate of $2 \mathrm{~mL} /$ hour throughout the experiment according to the published literature $[19,20]$. The 
plasma samples were immediately centrifuged at $6000 \mathrm{rpm}$ for $10 \mathrm{~min}$.

2.4. Sample Preparation. The biological samples were prepared by liquid-liquid extraction. The plasma and lymph samples ( $90 \mu \mathrm{L}$, resp.) spiked with $10 \mu \mathrm{L}$ of docetaxel solution (IS, $2.5 \mu \mathrm{g} / \mathrm{mL}$ ) were extracted by TBME for liquid-liquid extraction. Briefly, biological samples were extracted using $1 \mathrm{~mL}$ of TBME twice, vortexed for $5 \mathrm{~min}$, and centrifuged at $13,000 \mathrm{rpm}$ for $10 \mathrm{~min}$. After centrifugation, the upper organic layer containing the paclitaxel was transferred to a new tube and evaporated to dryness using a vacuum pump. The dried residue was reconstituted with $100 \mu \mathrm{L}$ of mobile phase (triple deionized water : methanol $=28: 72$ ) and analyzed by UPLCMS/MS. If the paclitaxel concentration was in excess of $500 \mathrm{ng} / \mathrm{mL}$, then the plasma and lymph samples were diluted by blank plasma and lymph samples at an appropriate ratio before analysis.

2.5. Preparation of Standard Samples. Stock solutions of paclitaxel and IS were prepared in methanol at a concentration of $1 \mathrm{mg} / \mathrm{mL}$. The calibration curves were obtained from biological samples freshly spiked with IS and the stock solution of paclitaxel at concentration ranges of $5-500 \mathrm{ng} / \mathrm{mL}$. The spiked biological samples were extracted following the sample preparation procedure described above.

2.6. Method Validation. The method validation assays for quantification of paclitaxel in rat plasma and lymphatic fluid were conducted based on the current US Food and Drug Administration (FDA) bioanalytical method validation guidelines [23]. Specificity, matrix effects, and recovery were evaluated. Biological samples were quantified using the ratio of the peak area of each analyte to that of the IS. Peak area ratios were plotted against analyte concentrations. All linear curves were required to have a coefficient of estimation of at least $>0.995$. Using the UPLC-MS/MS method described above, the intra- and interday variability were determined by quantitating six replicates at concentrations of $5,10,25$, $50,100,250$, and $500 \mathrm{ng} / \mathrm{mL}$ on the same day and on six consecutive days, respectively. The accuracy (\% bias) and the relative standard deviation (RSD \%) were calculated.

To evaluate matrix effect (ME) and recovery (RE), six different lots of blank plasma or lymph samples were extracted and then spiked with paclitaxel at three concentrations. The corresponding peak areas of paclitaxel in the spiked biological samples after extraction (A) were compared to those of the aqueous standards in mobile phase (B) at equivalent concentrations. The ratio $(\mathrm{A} / \mathrm{B} \times 100)$ is defined as the $\mathrm{ME}$. The corresponding peak areas of paclitaxel in the spiked biological samples before extraction (C) were compared to those of paclitaxel in the spiked biological samples after extraction (A) at equivalent concentrations. The ratio (C/A $\times 100)$ is defined as the RE.

2.7. Pharmacokinetic Data Analysis. Pharmacokinetic calculations were performed on each individual data set by noncompartmental methods using WinNonlin Standard Edition, version 1.1 (Pharsight Corp., Mountain View, CA).
2.8. Statistical Analysis. Data were summarized as the mean \pm $\mathrm{SD}$ or SEM. Comparison between two groups was performed using the unpaired Student's $t$-test. Statistical significance was set at $p<0.05$.

\section{Results}

3.1. Optimization of the UPLC-MS/MS Method. For parameter optimization, a standard solution of paclitaxel or docetaxel was analyzed by direct injection in the spectrometer. A full scan in the positive mode with precursor-product combinations monitored in the MRM mode was used for analyte identification. Paclitaxel and the IS could be ionized under positive $\left(\mathrm{ESI}^{+}\right)$electrospray ionization conditions. During initial infusion experiments with paclitaxel and docetaxel, the spectra revealed that both paclitaxel and docetaxel form $\mathrm{Na}^{+}$adducts. Under $\mathrm{ESI}^{+}$conditions, the precursor ions for paclitaxel and docetaxel were [paclitaxel $+\mathrm{Na}]^{+}$at $\mathrm{m} / \mathrm{z}$ 876.4 and [docetaxel $+\mathrm{Na}]^{+}$at $m / z$ 830.4, respectively. The MRM mode provided high selectivity and sensitivity for the quantification assay (Figure 1). The results of MS transitions demonstrate that the precursor ion of paclitaxel at $\mathrm{m} / \mathrm{z} 876.4$ $[\mathrm{M}+\mathrm{Na}]^{+}$and its main product ion at $m / z 308.1$ and the precursor ion of docetaxel at $m / z 830.4[\mathrm{M}+\mathrm{Na}]^{+}$and its main product ion at $m / z 549.2$ were used to determine the analytes in the biological samples. Chromatographic conditions were optimized for good sensitivity, peak shape, and a relatively short run. Methanol provided the best peak shape and was selected as the organic phase. A mobile phase consisting of a water-methanol solution (isocratic elution) was used in the experiment.

3.2. UPLC-MS/MS Method Validation of Paclitaxel in Rat Plasma and Lymph. Assay specificity was assessed by comparing the chromatograms of blank plasma and lymph samples obtained from six rats with corresponding spiked plasma and lymph samples. Each blank plasma and lymph sample was tested using a liquid-liquid extraction procedure and UPLC-MS/MS conditions to ensure no interference of paclitaxel and IS from plasma and lymph. The results showed that no interference existed under the present analytical conditions (Figures 2(a) and 2(d)).

Figures 2(a) and 2(d) show the chromatograms of a blank plasma and lymph extract with mass transitions of $m / z 876.4 \rightarrow 308.1$ for paclitaxel and $m / z 830.4 \rightarrow 549.2$ for docetaxel (IS), illustrating a clean baseline with no interference peaks eluted within $10 \mathrm{~min}$. Figures 2(b) and 2(e) show the chromatograms of a standard solution of paclitaxel $(250 \mathrm{ng} / \mathrm{mL})$ and IS $(250 \mathrm{ng} / \mathrm{mL})$ spiked in blank rat plasma and lymph. Figure $2(\mathrm{c})$ shows the chromatograms for a plasma sample containing paclitaxel $(270 \mathrm{ng} / \mathrm{mL})$ collected at $390 \mathrm{~min}$ after dosing with paclitaxel $(5 \mathrm{mg} / \mathrm{kg}$, i.v. infusion). Figure 2(f) shows the chromatograms for a lymph sample containing paclitaxel $(245 \mathrm{ng} / \mathrm{mL})$ collected from 330 to $360 \mathrm{~min}$ after dosing with paclitaxel $(5 \mathrm{mg} / \mathrm{kg}$, i.v. infusion). Each determination was completed within $10 \mathrm{~min}$ and no carry-over peaks were detected in the subsequent chromatograms of biological samples. 


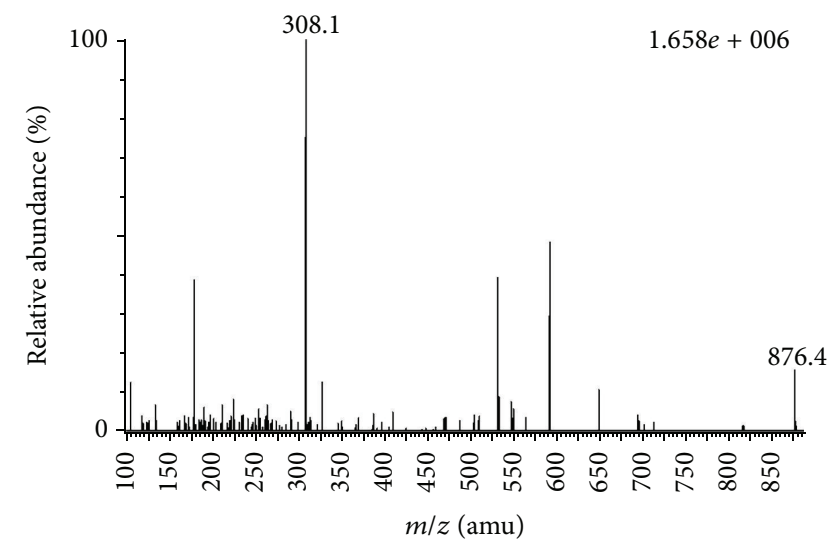

(a)

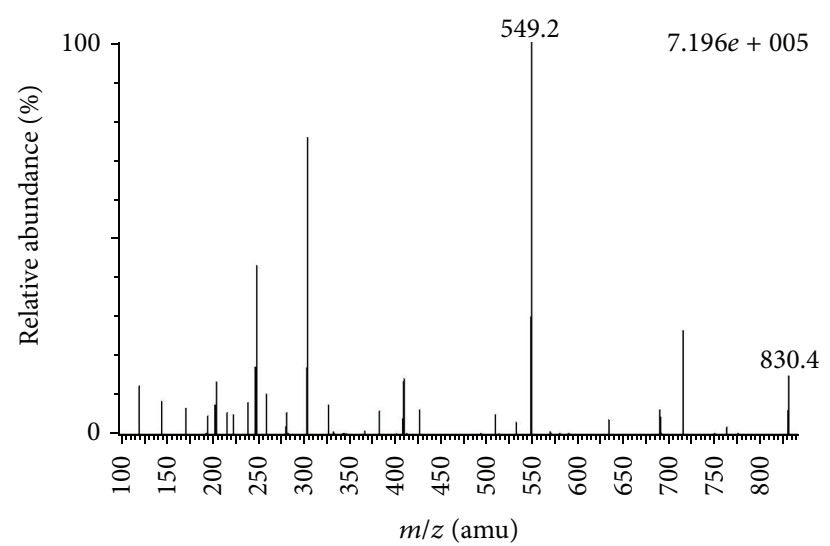

(b)

FIgURE 1: Mass spectra of (a) paclitaxel $(m / z 876.4 \rightarrow 308.1)$ and (b) docetaxel $(m / z 830.4 \rightarrow 549.2)$.

A $100 \%$ matrix effect value indicated that the response in the mobile phase and in the biological extracts was the same [20]. The mean matrix effects of paclitaxel and docetaxel (IS) in plasma were $106 \pm 14$ and $84 \pm 5 \%$, respectively; the mean matrix effects of paclitaxel and docetaxel (IS) in lymph were $80 \pm 7$ and $60 \pm 5 \%$, respectively (Table 1 ). The mean recovery for paclitaxel and IS in plasma was $85 \pm 13$ and $78 \pm 4 \%$, respectively; the mean recoveries for paclitaxel and IS in lymph were $84 \pm 11$ and $53 \pm 5 \%$, respectively (Table 1).

The calibration curve was constructed by plotting the peak area ratios of paclitaxel to the IS versus the concentrations of paclitaxel. The results demonstrated a linear response over the concentration ranges of $10-500 \mathrm{ng} / \mathrm{mL}$, with a coefficient of estimation $r^{2}>0.995$. The data showed excellent reproducibility (Table 2 ). The limit of detection (LOD) and quantification (LOQ) were defined as the concentration of paclitaxel detected as a signal-to-noise $(\mathrm{S} / \mathrm{N})$ ratio of 3 and 10 , respectively. The LOD and LOQ of paclitaxel in rat plasma and lymph were $5 \mathrm{ng} / \mathrm{mL}$ and the LOQ was $10 \mathrm{ng} / \mathrm{mL}$. The intra- and interday precision (\% RSD) and accuracy (\% bias) values of paclitaxel in rat plasma and lymph were within $15 \%$ (Table 2). These results show that the UPLC-MS/MS method provides excellent quantitative analysis of paclitaxel in rat plasma and lymph extracts.

3.3. Herb-Drug Interaction Effects of JWXYS on the Blood Pharmacokinetics of Paclitaxel. The mean plasma concentration-time profiles of paclitaxel after intravenous infusion of paclitaxel at $5 \mathrm{mg} / \mathrm{kg}(n=11)$ with or without pretreatment with JWXYS $(1.23 \mathrm{~g} / \mathrm{kg}$, p.o. for 7 days) are illustrated in Figure 3(a) and the pharmacokinetic parameters are listed in Table 3. Following 7 days of pretreatment with oral JWXYS at $1.23 \mathrm{~g} / \mathrm{kg}$, the AUC and $C_{\max }$ of paclitaxel in plasma were significantly reduced by approximately 1.5 -fold, compared to paclitaxel alone (Table 3). Additionally, the elimination halflife $\left(T_{1 / 2}\right)$ of paclitaxel in plasma was significantly prolonged 1.5 -fold; the total body clearance (CL) increased by $43 \%$ and the volume of distribution (Vd) significantly increased 1.4fold following coadministration with JWXYS. However, the mean residence time (MRT) exhibited no changes with or without pretreatment with JWXYS.

3.4. Herb-Drug Interaction Effects of JWXYS on the Lymph Pharmacokinetics of Paclitaxel. The mean concentrationtime profiles of paclitaxel in rat lymph $(n=11)$ after intravenous infusion of paclitaxel $(5 \mathrm{mg} / \mathrm{kg})$ with or without pretreatment with JWXYS (1.23 g/kg, p.o. for 7 days) are illustrated in Figure 3(b), and the pharmacokinetic parameters are illustrated in Table 3. As shown in Figure 3, the drug concentration versus time curve of paclitaxel in rat plasma and lymph after intravenous infusion of paclitaxel with or without pretreatment with JWXYS indicated that the amount of paclitaxel in rat lymph was lower than the amount of paclitaxel in rat plasma. Paclitaxel concentrations in plasma exceeded those in lymph by approximately 2.8 -fold, with AUC values of $315 \pm 38.2 \mathrm{~min} \mu \mathrm{g} / \mathrm{mL}$ in plasma and $113 \pm$ $12.7 \mathrm{~min} \mu \mathrm{g} / \mathrm{mL}$ in lymph. The $C_{\max }$ of paclitaxel in plasma was 3.6-fold greater than that in lymph.

Following 7 days of pretreatment with JWXYS, the AUC of paclitaxel in lymph was reduced by approximately 1.3fold and the $C_{\max }$ yielded similar results (Table 3 ). However, the $T_{1 / 2}, \mathrm{Vd}, \mathrm{CL}$, and MRT were not changed. The lymph absorption rate of paclitaxel $\left(\mathrm{AUC}_{\text {lymph }} / \mathrm{AUC}_{\text {plasma+lymph }} \times\right.$ 100) was $27 \pm 3 \%$, indicating that paclitaxel can be absorbed into the lymph system. However, pretreatment with JWXYS did not significantly affect the lymph absorption rate of paclitaxel $(30 \pm 2 \%)$ compared to paclitaxel alone. The biodistribution $\left(\mathrm{AUC}_{\text {lymph }} / \mathrm{AUC}_{\text {plasma }} \times 100\right)$ of paclitaxel from plasma to lymph was $39 \pm 5 \%$; however, it increased to $45 \pm$ $4 \%$ with JWXYS pretreatment. As shown in Figure 3, seven days of JWXYS at $1.23 \mathrm{~g} / \mathrm{kg}$ significantly decreased the blood paclitaxel levels by approximately $30 \%$ and reduced the distribution of paclitaxel in rat lymph by around $24 \%$.

\section{Discussion}

Although analytical methods have been reported for analysis of paclitaxel in biological matrices by high-performance 


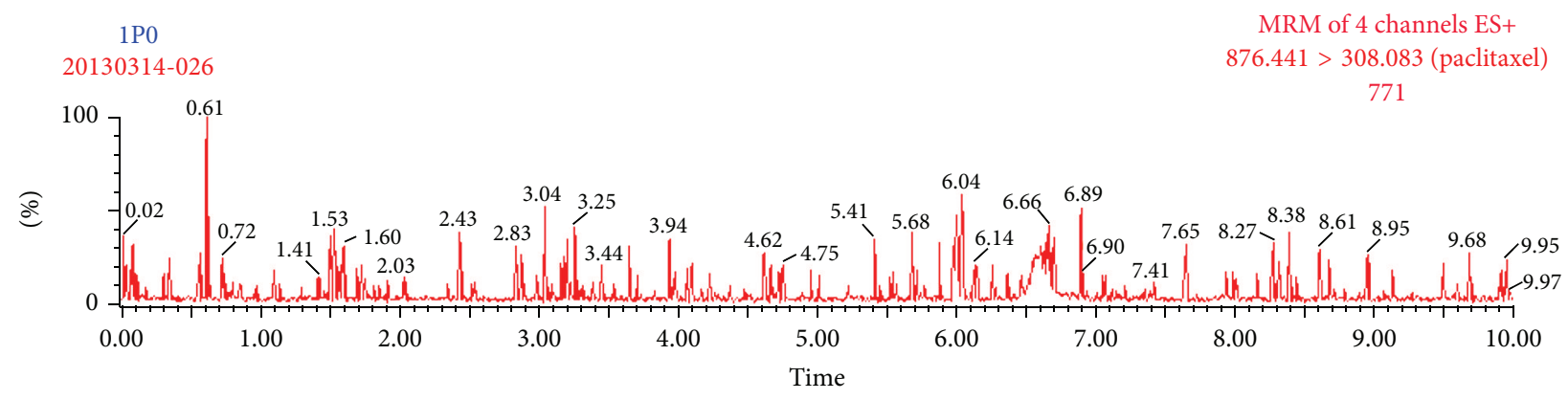

(a)

Plasma, PTX, $250 \mathrm{ppb}$

20131102-017

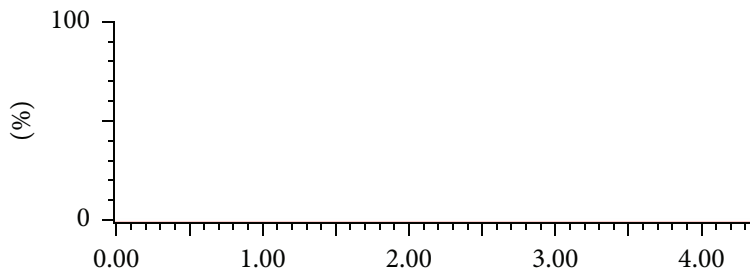

MRM of 4 channels ES+ $876.441>308.083$ (paclitaxel) $1.10 e 7$

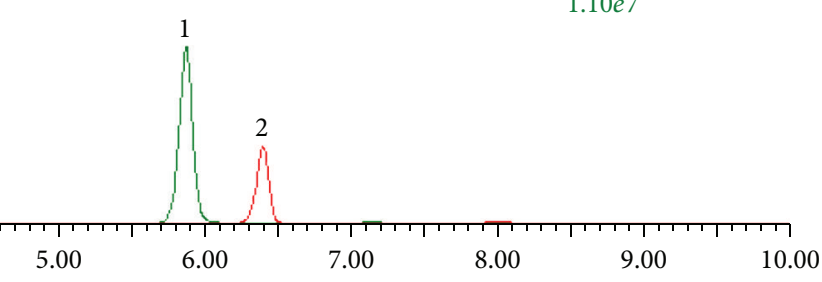

(b)

$16 \mathrm{P} 390$ 20131102-047

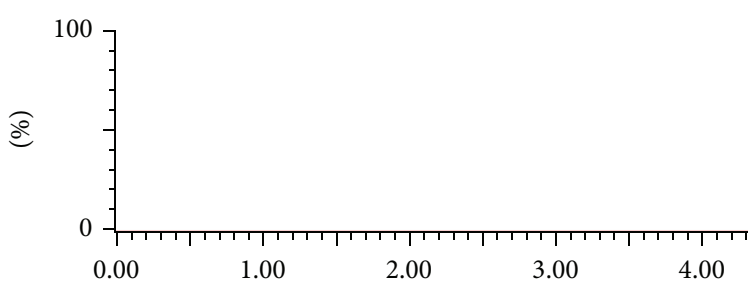

MRM of 4 channels ES+ $876.441>308.083$ (paclitaxel) $1.20 e 7$

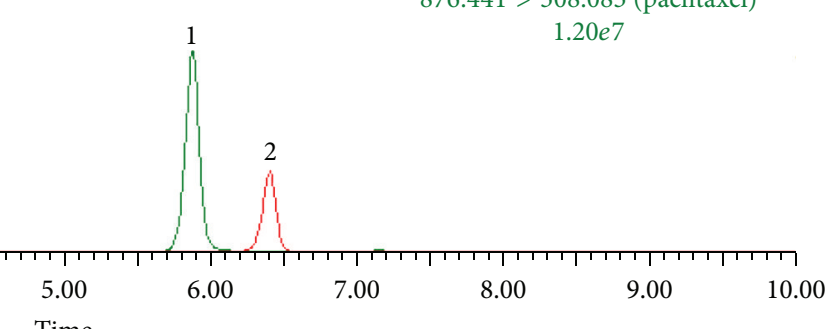

(c)

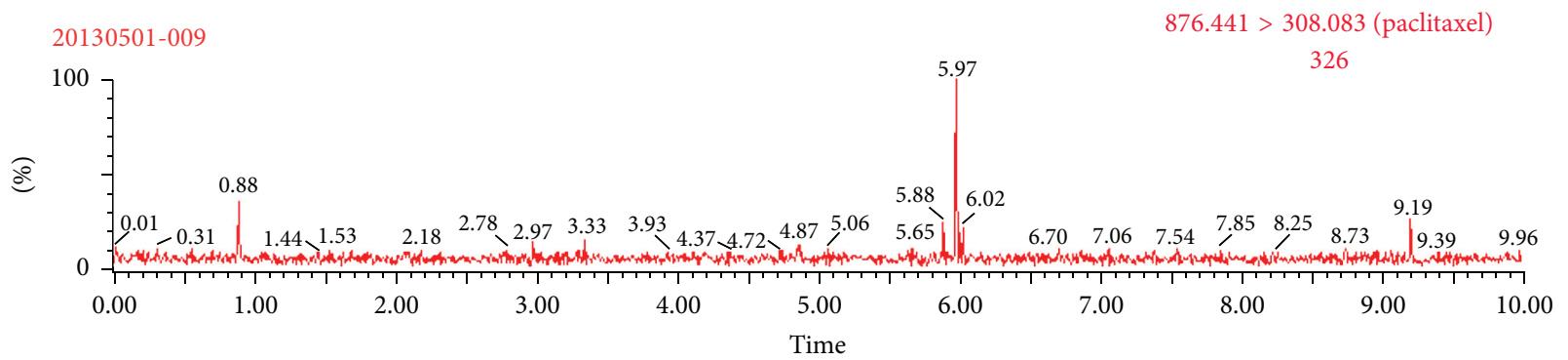

(d)

Lymph, PTX, $250 \mathrm{ppb}$ 20131107-017

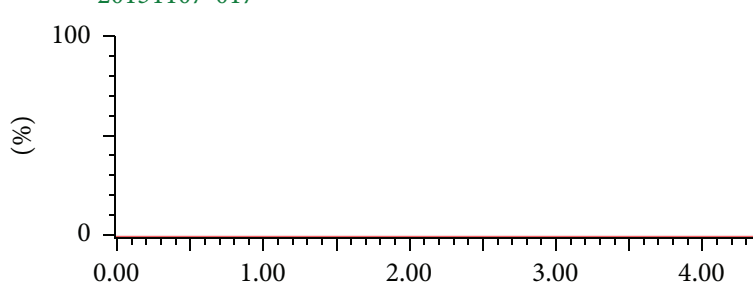

MRM of 4 channels ES+ $876.441>308.083$ (paclitaxel) $7.80 e 6$

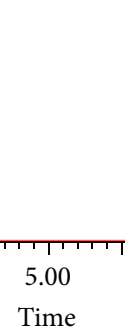

MRM of 4 channels ES+ $876.441>308.083$ (paclitaxel) 


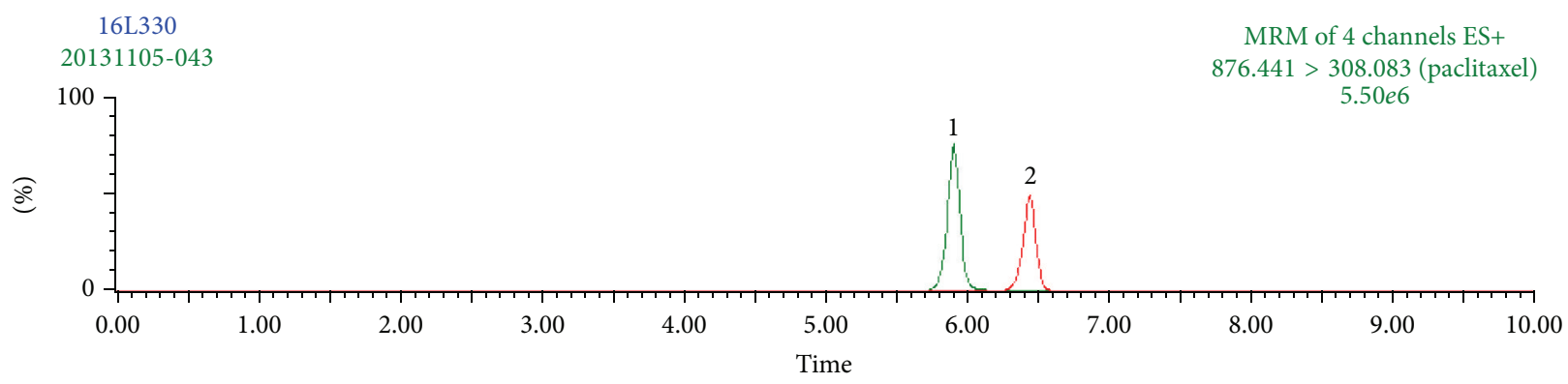

(f)

FIGURE 2: Representative chromatograms of paclitaxel in rat plasma and lymph. (a) Blank rat plasma; (b) blank rat plasma sample spiked with paclitaxel $(250 \mathrm{ng} / \mathrm{mL})$ and docetaxel (IS); (c) real rat plasma sample containing paclitaxel $(270 \mathrm{ng} / \mathrm{mL})$ collected at $390 \mathrm{~min}$ after administration of paclitaxel ( $5 \mathrm{mg} / \mathrm{kg}$, i.v. infusion). (d) Blank rat lymph; (e) blank rat lymph sample spiked with paclitaxel (250 ng/mL) and docetaxel (IS); (f) real rat lymph sample containing paclitaxel $(245 \mathrm{ng} / \mathrm{mL})$ collected from 330 to 360 min after administration of paclitaxel $(5 \mathrm{mg} / \mathrm{kg}$, i.v. infusion). 1: paclitaxel; 2: docetaxel (IS, $250 \mathrm{ng} / \mathrm{mL})$.

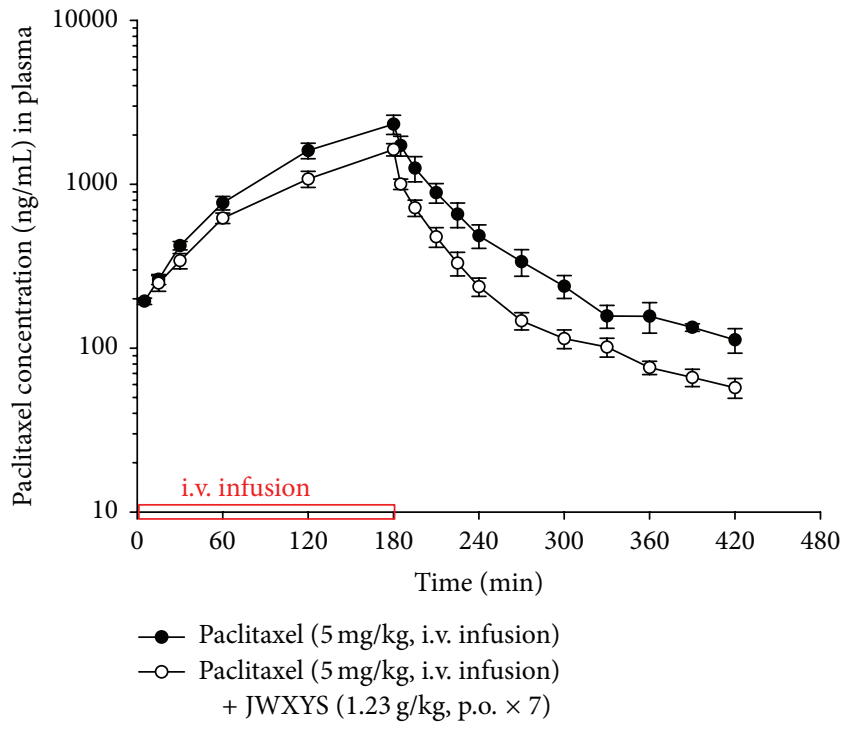

(a)

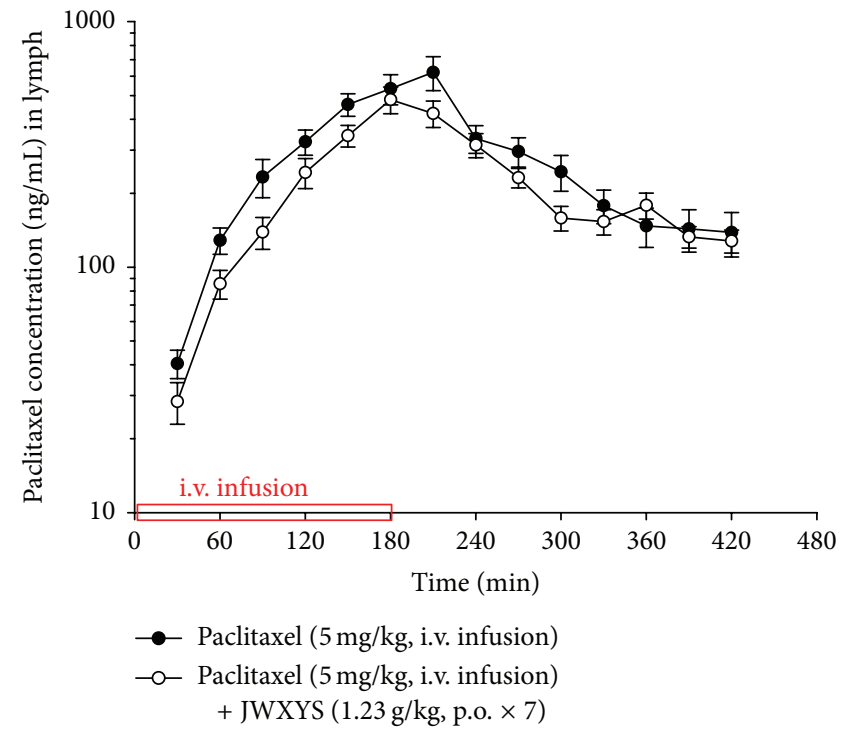

(b)

FIGURE 3: Mean concentration-time profiles of paclitaxel in rat plasma (a) and lymph (b) after intravenous infusion of paclitaxel (5 mg/kg) with or without JWXYS $(1.23 \mathrm{~g} / \mathrm{kg}$, p.o. for 7 days) pretreatment. Each point represents mean $\pm \operatorname{SEM}(N=11)$.

liquid chromatography with UV [24, 25], and by tandem mass spectrometric detection [26, 27], there is no validated method for the determination of paclitaxel in rat lymph. The MS transitions of paclitaxel $(\mathrm{m} / z$ 876.4 $\rightarrow 308.1)$ and docetaxel $(\mathrm{m} / z 830.4 \rightarrow 549.2)$ were in agreement with previous reports [27].

Numerous studies have indicated that the use of Chinese herbal medicines in combination with chemotherapy or radiotherapy for the treatment of cancer not only enhances the efficacy but also diminishes the side effects and complications induced by chemotherapy and radiotherapy treatments $[5-9,28]$. Chinese herbal medicines, including Astragalus, Turmeric, Ginseng, TJ-41, PHY-906, Huachansu infection, and Kanglaite injection, are commonly used by patients for cancer treatment and/or for the reduction of toxicity associated with chemotherapy and radiotherapy [29]. Studies on pharmacokinetic interactions between Chinese herbal medicines and Western medicines $[5,11,13,30]$ have been conducted, and the results suggest that oral administration of some phenolic substances might increase paclitaxel blood concentrations during chemotherapy. Because paclitaxel is a P-gp substrate, investigation on P-gp inhibition on the mesenteric lymphatic transport of paclitaxel has been reported [31]. The results demonstrated that pretreatment with a P-gp inhibitor, verapamil, increased the lymphatic transport of paclitaxel by 3.5-fold and absolute oral bioavailability by 1.8 -fold.

The bioactive components, including ferulic acid [32], atractylenolide I-III [33], paeoniflorin [34], saikosaponins [35], polysaccharides and triterpenoids [36], glycyrrhizin [37], paeonol [38], geniposide [39], zingerone [40], and chlorogenic acid [41], were found in the individual herb of 
TABLE 1: Matrix effect and recovery of paclitaxel and docetaxel in rat plasma and lymph.

\begin{tabular}{|c|c|c|c|c|c|}
\hline \multirow{2}{*}{ Nominal concentration $(\mathrm{ng} / \mathrm{mL})$} & \multicolumn{3}{|c|}{ Peak area } & \multirow{2}{*}{ Matrix effect (\%) } & \multirow{2}{*}{ Recovery (\%) } \\
\hline & Set 1 & Set 2 & Set 3 & & \\
\hline \multicolumn{6}{|l|}{ Plasma } \\
\hline \multicolumn{6}{|l|}{ Paclitaxel } \\
\hline 10 & $36872 \pm 4813$ & $32992 \pm 2473$ & $24279 \pm 2632$ & $89 \pm 7$ & $74 \pm 8$ \\
\hline 100 & $235603 \pm 12101$ & $269808 \pm 27215$ & $237379 \pm 31147$ & $115 \pm 12$ & $88 \pm 12$ \\
\hline 500 & $1202318 \pm 61512$ & $1356123 \pm 74986$ & $1265995 \pm 133390$ & $113 \pm 6$ & $93 \pm 10$ \\
\hline Average & & & & $106 \pm 14$ & $85 \pm 13$ \\
\hline \multicolumn{6}{|l|}{ Docetaxel (IS) } \\
\hline 250 & $465608 \pm 9230$ & $389823 \pm 23305$ & $302862 \pm 16985$ & $84 \pm 5$ & $78 \pm 4$ \\
\hline \multicolumn{6}{|l|}{ Lymph } \\
\hline \multicolumn{6}{|l|}{ Paclitaxel } \\
\hline 10 & $30372 \pm 3067$ & $25645 \pm 1935$ & $20778 \pm 2064$ & $84 \pm 6$ & $81 \pm 8$ \\
\hline 100 & $298923 \pm 18866$ & $246724 \pm 5850$ & $217499 \pm 35420$ & $83 \pm 2$ & $88 \pm 14$ \\
\hline 500 & $2216455 \pm 159883$ & $1598223 \pm 99812$ & $1341908 \pm 180573$ & $72 \pm 5$ & $84 \pm 11$ \\
\hline Average & & & & $80 \pm 7$ & $84 \pm 11$ \\
\hline \multicolumn{6}{|l|}{ Docetaxel (IS) } \\
\hline 250 & $465609 \pm 9330$ & $280022 \pm 21317$ & $147762 \pm 12713$ & $60 \pm 5$ & $53 \pm 5$ \\
\hline
\end{tabular}

Data expressed as mean \pm SD $(N=6)$. Matrix effect is expressed as the ratio of the mean peak area of an analyte spiked after extraction (set 2$)$ to the mean peak area of the same analyte standard (set 1) multiplied by 100 . A value of $>100 \%$ indicates ionization enhancement, and a value of $<100 \%$ indicates ionization suppression. Recovery was calculated as the ratio of the mean peak area of an analyte spiked before extraction (set 3 ) to the mean peak area of an analyte spiked after extraction (set 2) multiplied by 100 .

TABLE 2: Intra- and interday precision (\% RSD) and accuracy (\% bias) of the UPLC-MS/MS method for determination of paclitaxel in rat plasma and lymph (6 days, 6 replicates per day).

\begin{tabular}{|c|c|c|c|c|c|c|}
\hline \multirow[b]{2}{*}{$\begin{array}{l}\text { Nominal concentration } \\
(\mathrm{ng} / \mathrm{mL})\end{array}$} & \multicolumn{3}{|c|}{ Intraday } & \multicolumn{3}{|c|}{ Interday } \\
\hline & $\begin{array}{c}\text { Observed } \\
\text { concentration } \\
(\mathrm{ng} / \mathrm{mL})\end{array}$ & $\begin{array}{l}\text { Precision } \\
(\% \text { RSD) }\end{array}$ & $\begin{array}{l}\text { Accuracy } \\
\text { (\% bias) }\end{array}$ & $\begin{array}{c}\text { Observed } \\
\text { concentration } \\
(\mathrm{ng} / \mathrm{mL})\end{array}$ & $\begin{array}{l}\text { Precision } \\
\text { (\% RSD) }\end{array}$ & $\begin{array}{l}\text { Accuracy } \\
\text { (\% bias) }\end{array}$ \\
\hline \multicolumn{7}{|l|}{ Plasma } \\
\hline 10 & $9.58 \pm 1.28$ & 13.4 & -4.20 & $9.42 \pm 1.36$ & 14.4 & -5.77 \\
\hline 25 & $23.9 \pm 1.22$ & 5.13 & -4.51 & $24.8 \pm 2.11$ & 8.50 & -0.88 \\
\hline 50 & $49.5 \pm 2.90$ & 5.87 & -0.99 & $48.6 \pm 3.25$ & 6.69 & -2.88 \\
\hline 100 & $102 \pm 7.27$ & 7.10 & 2.45 & $99.1 \pm 2.46$ & 2.48 & -0.89 \\
\hline 250 & $259 \pm 9.80$ & 3.78 & 3.64 & $257 \pm 7.19$ & 2.80 & 2.76 \\
\hline 500 & $495 \pm 4.30$ & 0.87 & -1.05 & $497 \pm 4.17$ & 0.84 & -0.62 \\
\hline \multicolumn{7}{|l|}{ Lymph } \\
\hline 10 & $9.65 \pm 1.25$ & 12.9 & -3.49 & $9.21 \pm 1.26$ & 13.6 & -7.88 \\
\hline 25 & $25.1 \pm 2.67$ & 10.6 & 0.28 & $25.1 \pm 2.34$ & 9.34 & 0.25 \\
\hline 50 & $52.2 \pm 3.04$ & 5.83 & 4.34 & $52.4 \pm 3.47$ & 6.62 & 4.70 \\
\hline 100 & $101 \pm 4.32$ & 4.30 & 0.58 & $101 \pm 3.44$ & 3.39 & 1.42 \\
\hline 250 & $247 \pm 10.5$ & 4.26 & -1.32 & $248 \pm 14.2$ & 5.71 & -0.76 \\
\hline 500 & $502 \pm 4.94$ & 0.99 & 0.33 & $498 \pm 7.66$ & 1.54 & -0.37 \\
\hline
\end{tabular}

Data expressed as mean $\pm \mathrm{SD}$.

JWXYS. Studies on herb-drug interactions in pharmacokinetics based on metabolizing enzymes have been reported. For example, in vitro and in vivo studies showed that the potential components of Angelica sinensis (Oliv.) Diels roots, one of the major herbs in JWXYS, have the inhibitory effects on CYP3A4 [42]. It is known that lactones of Artemisia (ligustilide), n-butene acid lactones, ferulic acid, nicotinic acid, sucrose, amino acids, and sesquiterpene compounds are pharmacologically active components of Angelica sinensis (Oliv.) Diels [32]. Additionally, licorice root of Glycyrrhiza 
TABLE 3: Pharmacokinetic parameters of paclitaxel ( $5 \mathrm{mg} / \mathrm{kg}$, i.v. infusion) with or without JWXYS ( $1.23 \mathrm{~g} / \mathrm{kg}$, p.o. for 7 days) pretreatment.

\begin{tabular}{|c|c|c|}
\hline PK parameters & Paclitaxel (5 mg/kg, i.v. infusion) & Paclitaxel $(5 \mathrm{mg} / \mathrm{kg}$, i.v. infusion $)+J W X Y S(1.23 \mathrm{~g} / \mathrm{kg}$, p.o. $\times 7)$ \\
\hline \multicolumn{3}{|l|}{ Plasma } \\
\hline$C_{\max }(\mathrm{ng} / \mathrm{mL})$ & $2355 \pm 314$ & $1630 \pm 141^{*}$ \\
\hline $\mathrm{AUC}_{0-420 \min }(\min \mu \mathrm{g} / \mathrm{mL})$ & $315 \pm 38.2$ & $209 \pm 18.9^{*}$ \\
\hline$T_{1 / 2}(\min )$ & $73.7 \pm 12.2$ & $111 \pm 12.8^{*}$ \\
\hline $\mathrm{Vd}(\mathrm{L} / \mathrm{kg})$ & $1.39 \pm 0.15$ & $2.00 \pm 0.17^{*}$ \\
\hline $\mathrm{CL}(\mathrm{mL} / \mathrm{min} / \mathrm{kg})$ & $17.5 \pm 1.95$ & $25.1 \pm 2.55^{*}$ \\
\hline $\operatorname{MRT}(\min )$ & $68.6 \pm 3.70$ & $62.9 \pm 1.71$ \\
\hline \multicolumn{3}{|l|}{ Lymph } \\
\hline$C_{\max }(\mathrm{ng} / \mathrm{mL})$ & $648 \pm 94.3$ & $494 \pm 58.7$ \\
\hline $\mathrm{AUC}_{0-420 \min }(\min \mu \mathrm{g} / \mathrm{mL})$ & $113 \pm 12.7$ & $89.8 \pm 8.25$ \\
\hline$T_{1 / 2}(\min )$ & $116 \pm 17.6$ & $122 \pm 7.0$ \\
\hline $\mathrm{Vd}(\mathrm{L} / \mathrm{kg})$ & $8.08 \pm 1.59$ & $10.0 \pm 1.09$ \\
\hline $\mathrm{CL}(\mathrm{mL} / \mathrm{min} / \mathrm{kg})$ & $45.7 \pm 8.17$ & $48.3 \pm 4.36$ \\
\hline $\operatorname{MRT}(\min )$ & $119 \pm 4.77$ & $130 \pm 4.34$ \\
\hline Biodistribution (\%) & $39 \pm 5$ & $45 \pm 4$ \\
\hline Lymph absorption rate (\%) & $27 \pm 3$ & $30 \pm 2$ \\
\hline
\end{tabular}

Data expressed as mean $\pm \operatorname{SEM}(N=11) . C_{\max }$ : the peak plasma concentration of a drug after administration; AUC: area under the concentration versus time curve; $T_{1 / 2}$ : elimination half-life; Vd: volume of distribution; CL: total body clearance; MRT: mean residence time; biodistribution, $\left(\mathrm{AUC}_{\text {lymph }} / \mathrm{AUC} \mathrm{C}_{\mathrm{plasma}}\right) \times$ 100: the distribution of paclitaxel from plasma to lymph; lymph absorption rate, $\left[\left(\mathrm{AUC}_{\mathrm{lymph}} / \mathrm{AUC}_{\text {plasma+lymph }}\right) \times 100\right]$ : the lymph absorption rate of paclitaxel. ${ }^{*}$ Significantly different from paclitaxel alone at $p<0.05$.

uralensis Fisch. is another herbal component in JWXYS; its main active ingredient is glycyrrhizin [37]. In vitro studies have shown that isoflavone glabridin isolated from Glycyrrhiza uralensis Fisch could have CYP3A4 enzyme induction properties [42]. Furthermore, in vivo studies showed that repeated treatment with glycyrrhizae or glycyrrhizic acid could increase CYP3A4 substrate metabolism, and CYP3A4 was induced at both the mRNA and protein levels [42].

Our pharmacokinetic results demonstrate decreased blood and lymph paclitaxel concentrations following 7 days of pretreatment with JWXYS. However, pretreatment with JWXYS did not significantly influence the distribution and absorption rate of paclitaxel in lymph. The results suggest that orally administered JWXYS affects metabolizing enzymes as well as disturbing the distribution of paclitaxel into the circulation in vivo. The possible mechanism of interaction between JWXYS and paclitaxel could be increased metabolism of paclitaxel or affect transporter functions in the intestinal lymphatic system following oral administration of JWXYS; consequently, this would decrease paclitaxel levels in the peripheral and lymphatic system.

The lymphatic system plays an important role in fluid/ macromolecular balance, lipid absorption, and immune functions. It is involved in various pathologic conditions such as inflammation, spread of cancer cells, and lymphedema [43]. The lymphatic system can also transport dietary lipids, fat-soluble vitamins, and water-insoluble drugs to the systemic circulation. Paclitaxel has been approved to treat metastatic breast cancer [44]; however, limited evidence shows that paclitaxel can gain access to the lymphatic system.
The only literature is the one in which Cai et al. has investigated the effects of lipid vehicle and P-gp inhibition on the mesenteric lymphatic transport of paclitaxel [31]. Few reports regarding the absorption of drugs into the lymphatic system [45-49] have been investigated due to practical difficulties in obtaining the lymphatic fluid. Studies on the determination of protein or water-insoluble compounds in lymph and plasma following intravenous or intestinal administration in rats have been reported [45-49]. The results suggest that, over a given dose range, a protein with a high molecular weight can be absorbed in both the portal vein blood stream and the thoracic duct lymph after intraduodenal administration of parotin [48]. Our pharmacokinetic results demonstrate that paclitaxel was detectable in rat lymph after intravenous infusion of paclitaxel; however, JWXYS significantly decreased blood paclitaxel levels by approximately $30 \%$.

\section{Conclusions}

This is the first report to explore the herb-drug interaction effects of JWXYS on the pharmacokinetics of paclitaxel in rat peripheral and lymphatic systems. A validated UPLCMS/MS method was applied for pharmacokinetic studies. The pharmacokinetic results demonstrate that pretreatment with JWXYS for 7 days significantly attenuated the distribution of paclitaxel in rat peripheral and lymphatic systems. Clinically, it is not practical to collect lymphatic fluid in patients following paclitaxel administration. These findings indicate that monitoring plasma levels of paclitaxel may help in assessing compliance and therapeutic effects and in dose optimization when coadministered with JWXYS. 


\section{Competing Interests}

The authors declare that there are no competing interests.

\section{Acknowledgments}

Funding for this study was provided in part by research grants from the National Science Council (NSC102-2113-M-010-001MY3) Taiwan and TCH10401-62-004 and TCH104-02 from Taipei City Hospital, Taipei, Taiwan.

\section{References}

[1] M. Schmidt, "Chemotherapy in early breast cancer: when, how and which one?" Breast Care, vol. 9, no. 3, pp. 154-160, 2014.

[2] P. Ma and R. J. Mumper, "Paclitaxel nano-delivery systems: a comprehensive review," Journal of Nanomedicine and Nanotechnology, vol. 4, no. 2, Article ID 1000164, 2013.

[3] T. Iwamoto, "Clinical application of drug delivery systems in cancer chemotherapy: review of the efficacy and side effects of approved drugs," Biological and Pharmaceutical Bulletin, vol. 36, no. 5, pp. 715-718, 2013.

[4] V. Mandilaras, N. Bouganim, J. Spayne et al., "Concurrent chemoradiotherapy for locally advanced breast cancer-time for a new paradigm?" Current Oncology, vol. 22, no. 1, pp. 25-32, 2015.

[5] S. Y. K. Fong, Q. Gao, and Z. Zuo, "Interaction of carbamazepine with herbs, dietary supplements, and food: a systematic review," Evidence-Based Complementary and Alternative Medicine, vol. 2013, Article ID 898261, 15 pages, 2013.

[6] T. Makino, T. Inagaki, K.-I. Komatsu, and Y. Kano, "Pharmacokinetic interactions between Japanese traditional kampo medicine and modern medicine (IV). Effect of Kamisyoyosan and Tokisyakuyakusan on the pharmacokinetics of etizolam in rats," Biological and Pharmaceutical Bulletin, vol. 28, no. 2, pp. 280-284, 2005.

[7] S. Ohnishi and H. Takeda, "Herbal medicines for the treatment of cancer chemotherapy-induced side effects," Frontiers in Pharmacology, vol. 6, article 14, 2015.

[8] J.-N. Lai, C.-T. Wu, and J.-D. Wang, "Prescription pattern of Chinese herbal products for breast cancer in Taiwan: a population-based study," Evidence-Based Complementary and Alternative Medicine, vol. 2012, Article ID 891893, 7 pages, 2012.

[9] B.-R. Wang, Y.-L. Chang, T.-J. Chen et al., "Coprescription of Chinese herbal medicine and Western medication among female patients with breast cancer in Taiwan: analysis of national insurance claims," Patient Preference and Adherence, vol. 8, pp. 671-682, 2014.

[10] B. Rochat, "Role of cytochrome P450 activity in the fate of anticancer agents and in drug resistance: focus on tamoxifen, paclitaxel and imatinib metabolism," Clinical Pharmacokinetics, vol. 44, no. 4, pp. 349-366, 2005.

[11] J. Jin, H. Bi, J. Hu et al., "Effect of Wuzhi tablet (Schisandra sphenanthera extract) on the pharmacokinetics of paclitaxel in rats," Phytotherapy Research, vol. 25, no. 8, pp. 1250-1253, 2011.

[12] J. H. Park, J. H. Park, H. J. Hur, J. S. Woo, and H. J. Lee, "Effects of silymarin and formulation on the oral bioavailability of paclitaxel in rats," European Journal of Pharmaceutical Sciences, vol. 45, no. 3, pp. 296-301, 2012.

[13] R. Václavíková, S. Horský, P. Šimek, and I. Gut, "Paclitaxel metabolism in rat and human liver microsomes is inhibited by phenolic antioxidants," Naunyn-Schmiedeberg's Archives of Pharmacology, vol. 368, no. 3, pp. 200-209, 2003.

[14] J. H. Lee, A. Lee, J.-H. Oh, and Y.-J. Lee, "Comparative pharmacokinetic study of paclitaxel and docetaxel in streptozotocininduced diabetic rats," Biopharmaceutics and Drug Disposition, vol. 33, no. 8, pp. 474-486, 2012.

[15] A. R. Tan, A. Dowlati, M. N. Stein et al., "Phase I study of weekly paclitaxel in combination with pazopanib and lapatinib in advanced solid malignancies," British Journal of Cancer, vol. 110, no. 11, pp. 2647-2654, 2014.

[16] X. Wang, L. Song, N. Li et al., "Pharmacokinetics and biodistribution study of paclitaxel liposome in Sprague-Dawley rats and Beagle dogs by liquid chromatography-tandem mass spectrometry," Drug Research, vol. 63, no. 11, pp. 603-606, 2013.

[17] C.-M. Lu, M.-L. Hou, L.-C. Lin, and T.-H. Tsai, "Chemical and physical methods to analyze a multicomponent traditional chinese herbal prescription using LC-MS/MS, electron microscope, and congo red staining," Evidence-Based Complementary and Alternative Medicine, vol. 2013, Article ID 952796, 10 pages, 2013.

[18] S. Reagan-Shaw, M. Nihal, and N. Ahmad, "Dose translation from animal to human studies revisited," FASEB Journal, vol. 22, no. 3, pp. 659-661, 2008.

[19] M. Boyd, V. Risovic, P. Jull, E. Choo, and K. M. Wasan, "A stepwise surgical procedure to investigate the lymphatic transport of lipid-based oral drug formulations: cannulation of the mesenteric and thoracic lymph ducts within the rat," Journal of Pharmacological and Toxicological Methods, vol. 49, no. 2, pp. 115-120, 2004.

[20] M. Ionac, "One technique, two approaches, and results: thoracic duct cannulation in small laboratory animals," Microsurgery, vol. 23, no. 3, pp. 239-245, 2003.

[21] C. H. Hsieh, M. L. Hou, L. Y. Wang, H. Tai, T. Tsai, and Y. Chen, "Local pelvic irradiation modulates pharmacokinetics of 5 -fluorouracil in the plasma but not in the lymphatic system," BMC Cancer, vol. 15, no. 1, article 316, 2015.

[22] T.-H. Tsai, Y.-J. Chen, M.-L. Hou, L.-Y. Wang, H.-C. Tai, and C.H. Hsieh, "Pelvic irradiation modulates the pharmacokinetics of cisplatin in the plasma and lymphatic system," American Journal of Translational Research, vol. 7, no. 2, pp. 375-384, 2015.

[23] D. Zimmer, "New US FDA draft guidance on bioanalytical method validation versus current FDA and EMA guidelines: chromatographic methods and ISR," Bioanalysis, vol. 6, no. 1, pp. 13-19, 2014.

[24] A. Jain, A. Gulbake, A. Jain et al., "Development and validation of the HPLC method for simultaneous estimation of paclitaxel and topotecan," Journal of Chromatographic Science, vol. 52, no. 7, pp. 697-703, 2014.

[25] S. S. Vasudev, F. J. Ahmad, R. K. Khar et al., "Validated HPLC method for the simultaneous determination of taxol and ellagic acid in a Punica granatum fruit extract containing combination formulation," Pharmazie, vol. 67, no. 10, pp. 834-838, 2012.

[26] J. Carlier, J. Guitton, L. Romeuf et al., "Screening approach by ultra-high performance liquid chromatography-tandem mass spectrometry for the blood quantification of thirty-four toxic principles of plant origin. Application to forensic toxicology," Journal of Chromatography B: Analytical Technologies in the Biomedical and Life Sciences, vol. 975, pp. 65-76, 2015.

[27] B. Liu, X. Gou, X. Bai et al., "Simultaneous determination of seven taxoids in rat plasma by UPLC-MS/MS and pharmacokinetic study after oral administration of Taxus yunnanensis 
extracts," Journal of Pharmaceutical and Biomedical Analysis, vol. 107, pp. 346-354, 2015.

[28] J. A. Siddiqui, A. Singh, M. Chagtoo, N. Singh, M. Godbole, and B. Chakravarti, "Phytochemicals for breast cancer therapy: current status and future implications," Current Cancer Drug Targets, vol. 15, no. 2, pp. 116-135, 2015.

[29] F. Qi, A. Li, Y. Inagaki et al., "Chinese herbal medicines as adjuvant treatment during chemoor radio-therapy for cancer," BioScience Trends, vol. 4, no. 6, pp. 297-307, 2010.

[30] K. K. Kumar, L. Priyanka, K. Gnananath, P. R. Babu, and S. Sujatha, "Pharmacokinetic drug interactions between apigenin, rutin and paclitaxel mediated by P-glycoprotein in rats," European Journal of Drug Metabolism and Pharmacokinetics, vol. 40, no. 3, pp. 267-276, 2015.

[31] Q. Cai, X. Deng, Z. Li, D. An, T. Shen, and M. Zhong, "Effects of lipid vehicle and P-glycoprotein inhibition on the mesenteric lymphatic transport of paclitaxel in unconscious, lymph ductcannulated rats," Drug Delivery, vol. 23, no. 1, pp. 147-153, 2014.

[32] L.-Y. Wang, Y.-P. Tang, X. Liu et al., "Effects of ferulic acid on antioxidant activity in Angelicae Sinensis Radix, Chuanxiong Rhizoma, and their combination," Chinese Journal of Natural Medicines, vol. 13, no. 6, pp. 401-408, 2015.

[33] G.-S. Shan, L.-X. Zhang, Q.-M. Zhao et al., "Metabolomic study of raw and processed Atractylodes macrocephala Koidz by LCMS," Journal of Pharmaceutical and Biomedical Analysis, vol. 98, pp. 74-84, 2014.

[34] Y. Ji, T. Wang, Z.-F. Wei et al., "Paeoniflorin, the main active constituent of Paeonia lactiflora roots, attenuates bleomycininduced pulmonary fibrosis in mice by suppressing the synthesis of type I collagen," Journal of Ethnopharmacology, vol. 149, no. 3, pp. 825-832, 2013.

[35] B. Y.-K. Law, J.-F. Mo, and V. K.-W. Wong, "Autophagic effects of Chaihu (dried roots of Bupleurum Chinense DC or Bupleurum scorzoneraefolium WILD)," Chinese Medicine, vol. 9, no. 1, article 21, 2014.

[36] J.-L. Ríos, "Chemical constituents and pharmacological properties of Poria cocos," Planta Medica, vol. 77, no. 7, pp. 681-691, 2011.

[37] X. Wang, H. Zhang, L. Chen, L. Shan, G. Fan, and X. Gao, "Liquorice, a unique 'guide drug' of traditional Chinese medicine: a review of its role in drug interactions," Journal of Ethnopharmacology, vol. 150, no. 3, pp. 781-790, 2013.

[38] C. H. Lau, C. M. Chan, Y. W. Chan et al., "Pharmacological investigations of the anti-diabetic effect of Cortex Moutan and its active component paeonol," Phytomedicine, vol. 14, no. 11, pp. 778-784, 2007.

[39] S. Cheng, L.-C. Lin, C.-H. Lin, and T.-H. Tsai, "Comparative oral bioavailability of geniposide following oral administration of geniposide, Gardenia jasminoides Ellis fruits extracts and Gardenia herbal formulation in rats," Journal of Pharmacy and Pharmacology, vol. 66, no. 5, pp. 705-712, 2014.

[40] B. Ahmad, M. U. Rehman, I. Amin et al., "A review on pharmacological properties of zingerone (4-(4-Hydroxy-3-methoxyphenyl)-2-butanone)," The Scientific World Journal, vol. 2015, Article ID 816364, 6 pages, 2015.

[41] W. J. Zhang, K. Yang, C. X. You et al., "Contact toxicity and repellency of the essential oil from Mentha haplocalyx Briq. against Lasioderma serricorne," Chemistry \& Biodiversity, vol. 12, no. 5, pp. 832-839, 2015.

[42] C.-X. Liu, X.-L. Yi, D.-Y. Si, X.-F. Xiao, X. He, and Y.-Z. Li, "Herb-drug interactions involving drug metabolizing enzymes and transporters," Current Drug Metabolism, vol. 12, no. 9, pp. 835-849, 2011.

[43] A. A. Gashev, "Physiologic aspects of lymphatic contractile function: current perspectives," Annals of the New York Academy of Sciences, vol. 979, pp. 178-187, 2002.

[44] S. Binder, "Evolution of Taxanes in the treatment of metastatic breast cancer," Clinical Journal of Oncology Nursing, vol. 17, no. 1, pp. 9-14, 2013.

[45] A. C. Boileau, N. R. Merchen, K. Wasson, C. A. Atkinson, and J. W. Erdman Jr., "Cis-lycopene is more bioavailable than translycopene in vitro and in vivo in lymph-cannulated ferrets," Journal of Nutrition, vol. 129, no. 6, pp. 1176-1181, 1999.

[46] I.-L. Chen, Y.-J. Tsai, C.-M. Huang, and T.-H. U. Tsai, "Lymphatic absorption of quercetin and rutin in rat and their pharmacokinetics in systemic plasma," Journal of Agricultural and Food Chemistry, vol. 58, no. 1, pp. 546-551, 2010.

[47] W. Faisal, C. M. O’Driscoll, and B. T. Griffin, "Bioavailability of lycopene in the rat: the role of intestinal lymphatic transport," Journal of Pharmacy and Pharmacology, vol. 62, no. 3, pp. 323331, 2010.

[48] H. Manita, T. Sudo, and H. Asano, "Demonstration of parotin in thoracic duct lymph and portal vein blood upon intestinal administration in the rat," Endocrinologia Japonica, vol. 20, no. 5, pp. 463-474, 1973.

[49] Y.-J. Tsai and T.-H. Tsai, "Mesenteric lymphatic absorption and the pharmacokinetics of naringin and naringenin in the rat," Journal of Agricultural and Food Chemistry, vol. 60, no. 51, pp. 12435-12442, 2012. 


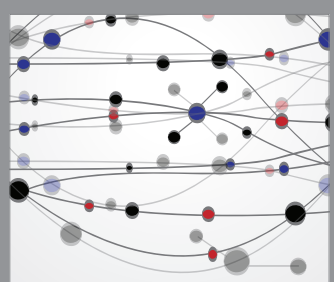

The Scientific World Journal
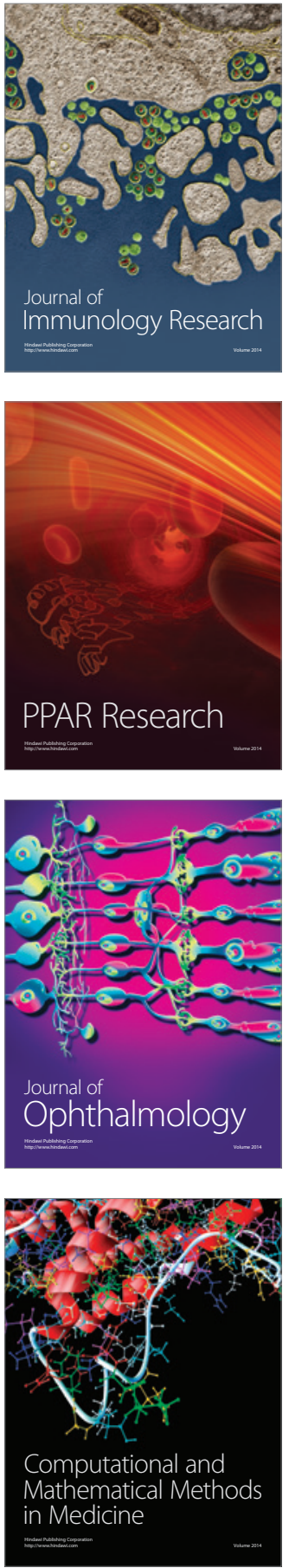

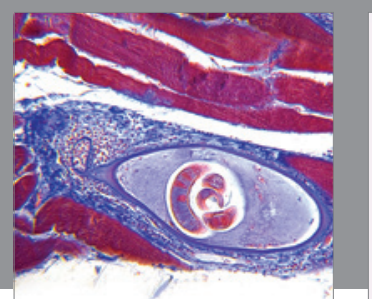

Gastroenterology Research and Practice

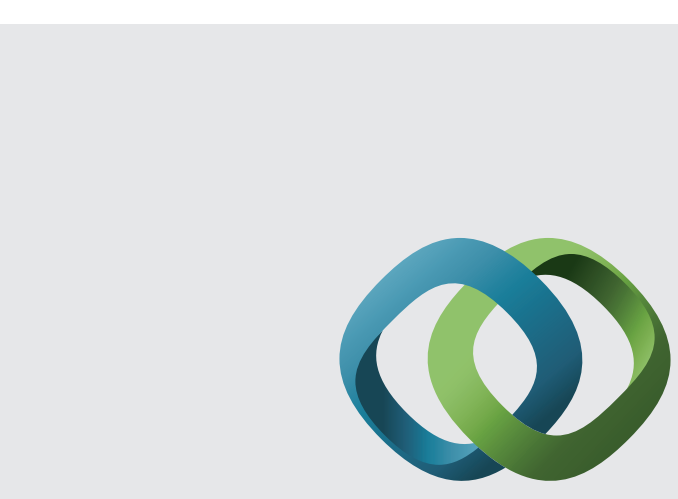

\section{Hindawi}

Submit your manuscripts at

http://www.hindawi.com
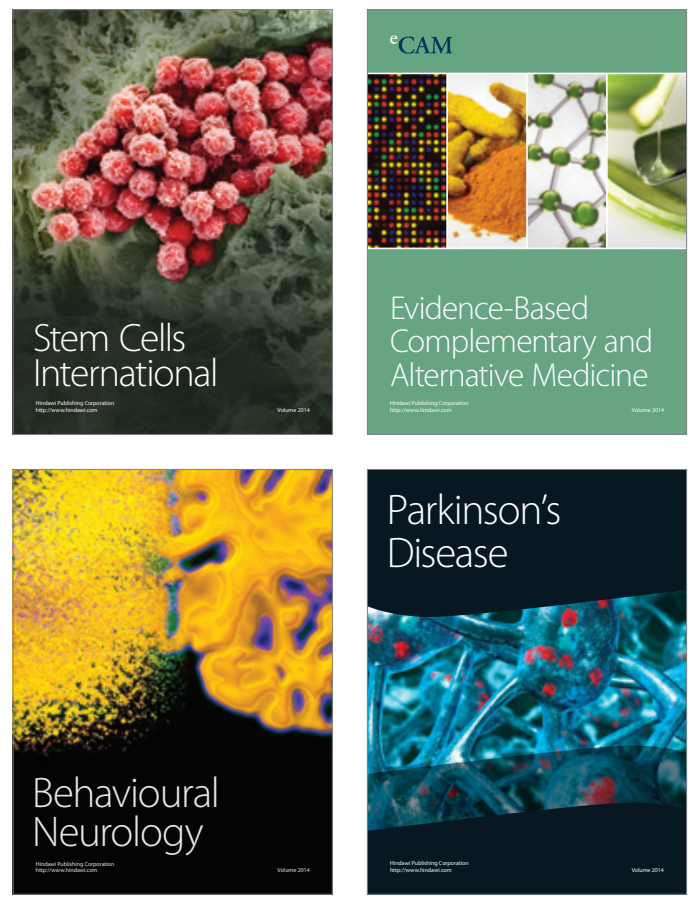
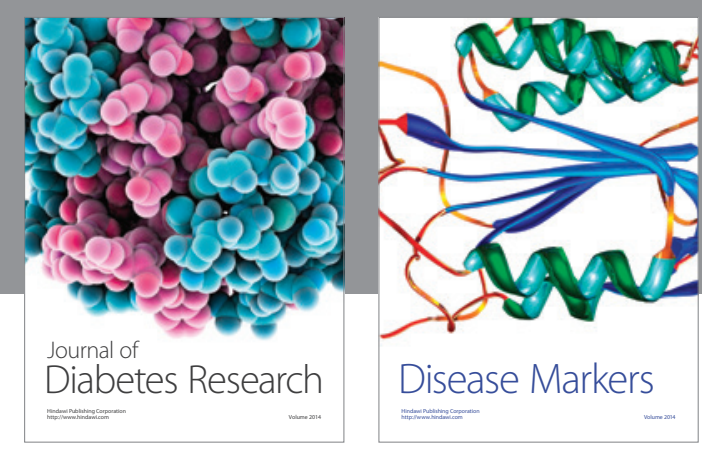

Disease Markers
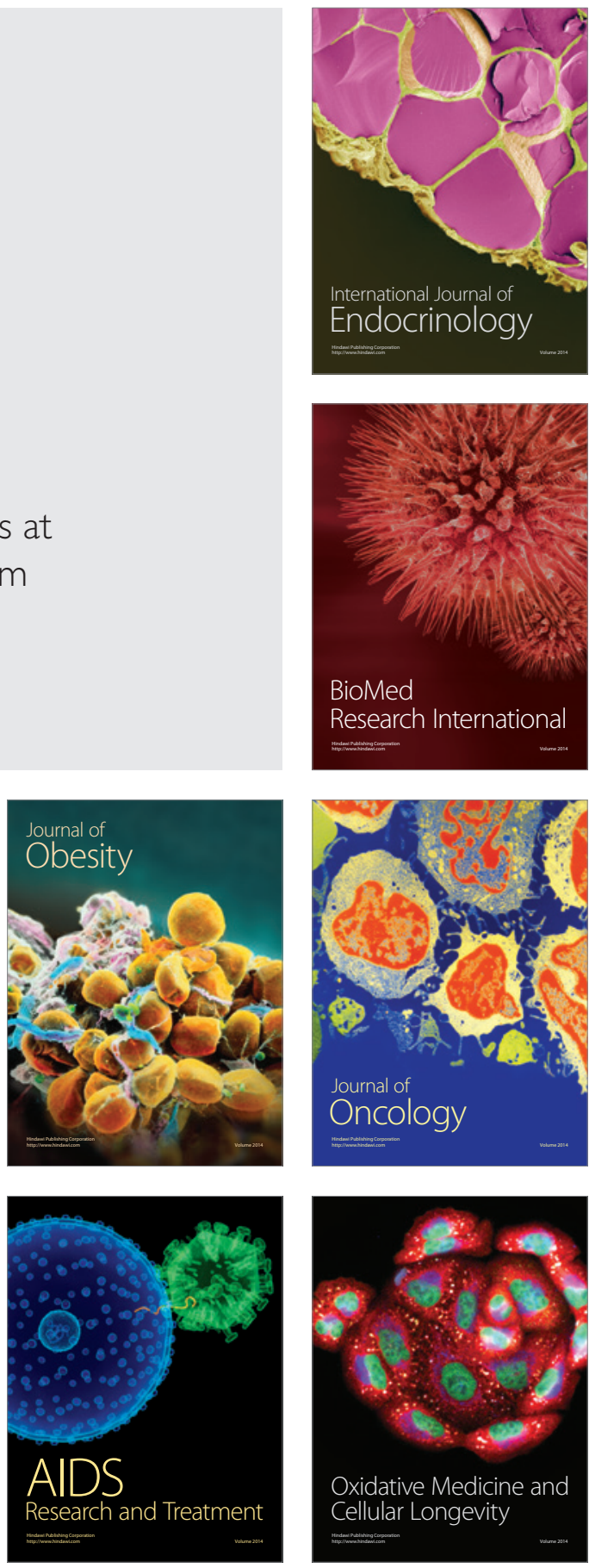